
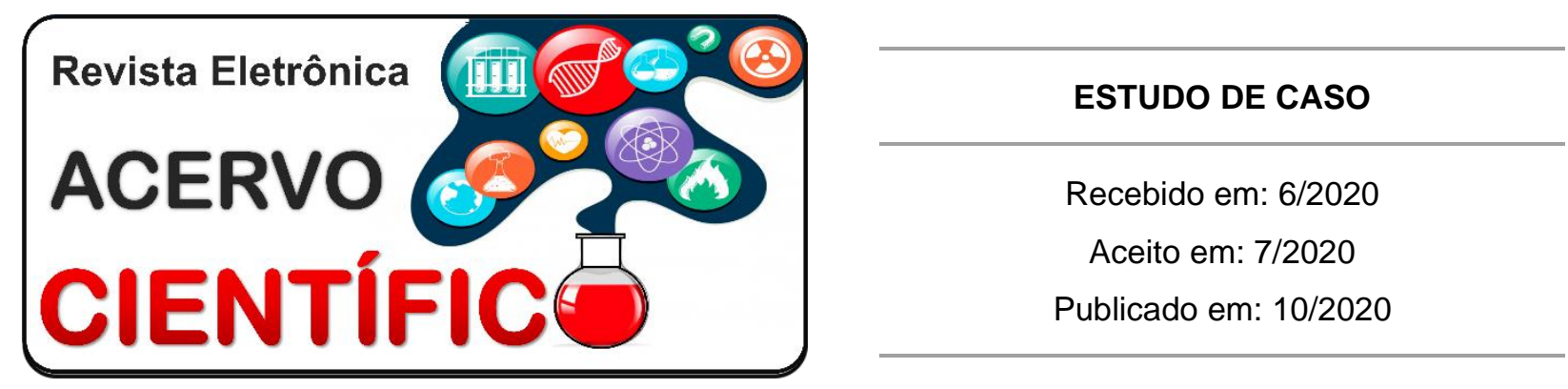

\title{
Radioterapia hipofracionada no controle álgico e local do câncer de couro cabeludo destruindo calota craniana: apresentação de caso atípico
}

Hypohrated radiotherapy in the algic and local control of hairy leather cancer destroying cranial cap: presentation of atypical case

Radioterapia hipófrada em el agua y control local del cáncer de piel pelo destruyendo tapa craneal: presentación del caso atípico

Vinicius Francisco Fernandes Rodrigues ${ }^{1 *}$, Yanka Rafaela da Costa Neto Vieira ${ }^{1}$, Darlinton Cardoso Fonseca ${ }^{1}$, Murilo Brandão Pimenta ${ }^{1}$, Ana Paula Ramos de Souza1, Patrícia Reis Valente $^{1}$, James Santos Aguiar ${ }^{1}$, Thayná Silva Cotrim ${ }^{1}$, Karolyne Bezerra de Oliveira ${ }^{1}$, Priscila Santos da Conceição².

Resumo: No presente estudo de caso, apresentamos o relato de uma radioterapia hipofracionada realizada em paciente com câncer de pele não melanoma em couro cabeludo, destruindo sua calota craniana e ocasionando dor intensa. Paciente veio à primeira consulta em serviço de radioterapia referindo ter percebido "feridinha" em couro cabeludo há 6 meses, que por vergonha de expor à família tratou apenas com curativos. Paciente apresentou-se em bom estado geral, Escala de Performance Karnofsky (KPS): $90 \%$, apresentando-se com lesão úlcero-infiltrativa destrutiva localizada em região parieto-occipital direita, com extensão $>25 \mathrm{~cm}$ de diâmetro, destruindo couro cabeludo, calota craniana e infiltrando parênquima cerebral adjacente, com áreas necróticas e permeadas de pontos de sangramento, associado a odor fétido. O diagnóstico precoce desse tipo de câncer é recomendado para toda a população, necessitando que todos estejam atentos às suas principais formas de apresentação. Enfatiza-se a necessidade de sua prevenção com ações de educação em saúde direcionadas à população, com estímulo a proteção individual e atuação sobre elementos modificadores da doença.

Palavras-chave: Neoplasias, Neoplasias de cabeça e pescoço, Radioterapia.

Abstract: In the present case study, we present the report of a low-radiation radiotherapy performed on a patient with non-melanoma skin cancer on the scalp, destroying his skullcap and causing severe pain. The patient came to the first consultation at a radiotherapy service, reporting that he had noticed a "wound" on the scalp 6 months ago, which, ashamed of exposing it to the family, treated it only with bandages. Patient presented in good general condition, Karnofsky Performance Scale (KPS): 90\%, presenting with destructive ulcerative infiltrative lesion located in the right parieto-occipital region, with extension $>25 \mathrm{~cm}$ in diameter,

${ }^{1}$ Centro Universitário Metropolitano da Amazônia (UNIFAMAZ), Belém - PA.

${ }^{*}$ E-mail: fernandesvfr@gmail.com

${ }^{2}$ Centro Universitário do Pará (CESUPA), Belém - PA. 
destroying scalp, skullcap and infiltrating adjacent cerebral parenchyma, with necrotic areas and permeated with bleeding points, associated with a foul odor. Early diagnosis of this type of cancer is recommended for the entire population, requiring everyone to be aware of its main forms of presentation. The need for its prevention is emphasized with health education actions aimed at the population, encouraging individual protection and acting on elements that modify the disease.

Keywords: Neoplasms, Head and neck neoplasms, Radiotherapy.

Resumen: En el presente estudio de caso, presentamos el informe de una radioterapia de baja radiación realizada en un paciente con cáncer de piel no melanoma en el cuero cabelludo, destruyendo su cráneo y causando dolor severo. El paciente acudió a la primera consulta en un servicio de radioterapia, informando que había notado una "herida" en el cuero cabelludo hace 6 meses, que, avergonzado de exponerlo a la familia, lo trató solo con vendas. Paciente presentado en buen estado general, Escala de rendimiento de Karnofsky (KPS): 90\%, que presenta una lesión infiltrativa ulcerosa destructiva ubicada en la región parietooccipital derecha, con extensión $>25 \mathrm{~cm}$ de diámetro, destruyendo cuero cabelludo, cráneo e infiltrando parénquima cerebral adyacente, con áreas necróticas e impregnadas de puntos de sangrado, asociado con un olor desagradable. El diagnóstico precoz de este tipo de cáncer se recomienda para toda la población, lo que requiere que todos conozcan sus principales formas de presentación. La necesidad de su prevención se enfatiza con acciones de educación sanitaria dirigidas a la población, fomentando la protección individual y actuando sobre los elementos que modifican la enfermedad.

Palabras clave: Neoplasias, Neoplasias de cabeza y cuello, Radioterapia.

\section{INTRODUÇÃO}

A nível mundial, o câncer de pele não melanoma (CPNM) representa a neoplasia maligna mais diagnosticada em ambos os sexos. Também é o câncer mais comum no Brasil, onde corresponde a cerca de $30 \%$ de todos os tumores registrados, sendo mais incidente nas regiões Sul, Centro-Oeste e Sudeste, respectivamente (COSTA GLG, 2017). Em 2018, ocorreram no país um total de 2.250 mortes por essa comorbidade. Ainda assim, segundo dados do Instituto Nacional do Câncer (INCA) número de casos novos de câncer de pele não melanoma será de 93.160 em mulheres e de 83.770 em homens para cada ano do triênio 2020-2022 (BRASIL, 2016).

As populações de pele clara residentes em países com alta exposição a radiações ultravioletas (Austrália e Nova Zelândia, América do Norte e nos países da Europa Ocidental) têm maior risco de desenvolver CPNM, à medida que a população envelhece, especialmente em regiões de cabeça e pescoço, as quais são mais expostas ao sol. Assim, ocasionando um impacto reconhecido na qualidade de vida do paciente com morbimortalidade associada (BRAY F, et al., 2018; VENES MJ, et al., 2019).

Essa neoplasia possui etiologia diversificada, associada a fatores ambientais, genéticos e ao estilo de vida da população (COSTA GLG, 2017). No entanto é decorrente principalmente da exposição à radiação ultravioleta, seja pela exposição direta à luz solar ou por fontes artificiais de luz como o bronzeamento artificial. A lesão tecidual ocasionada pela radiação pode levar a lesão no Ácido Desoxirribonucleico (DNA) e reparo inadequado do tecido lesado, resultando em câncer (LONG DL, et al., 2013).

Também é mais prevalente em pessoas acima dos 40 anos com história pessoal ou familiar. Porém, nos últimos anos, esse perfil epidemiológico de idade vem se modificando com a maior utilização das práticas de bronzeamento artificial e, a cada vez mais, constante exposição dos jovens aos raios solares (BRASIL, 2016).

Outros fatores de risco são a infecção por Vírus da Imunodeficiência Humana (HIV), exposição à radiação ionizante, cicatrizes de queimadura térmica e úlceras crônicas. Encontram-se na literatura relação com a exposição a agentes químicos (arsênico), processo irritativo crônico (úlcera de Marjolin), genodermatoses, albinismo e disceratose congênita (LONG DL, et al., 2013). 
Os principais tipos de câncer de pele não melanoma são o carcinoma basocelular e o carcinoma de células escamosas (CCE) (COSTA GLG, 2017). O CCE apresenta um curso clínico variável, oscilando de uma cinética de crescimento rápido a indolente, com o potencial metastático para sítios regionais e distantes. Normalmente, o CCE apresenta-se como um nódulo eritematoso ulcerado ou uma erosão superficial na pele exposta ao sol, como cabeça, pescoço, tronco e extremidades. Ele poderá surgir como uma simples pápula, firme, de forma curva ou uma placa de textura áspera. Comumente é confundido com uma verruga ou calo quando a resposta inflamatória à lesão é mínima (LONG DL, et al., 2013).

A grande maioria dos CPNM pode ser curada cirurgicamente, mas quando há impossibilidade desta abordagem em carcinomas avançados local ou regionalmente e em quadros de metástases à distância, as opções de tratamento e a sobrevida do paciente são limitadas. Radioterapia, quimioterapia citotóxica, cetuximabe, isoladamente ou em combinação, e panitumumabe podem ser utilizados (LAVAUD J, et al., 2019).

Muitos pacientes possuem lesão ocasionada pelo carcinoma de pele não melanoma tecnicamente inoperável e, se não forem tratados, sofrem de morbidade local, com dor e sangramento. Afetando em suas qualidades de vidas e a de seus cuidadores. É nesta coorte de pacientes que a radioterapia hipofracionada, administrada diariamente ou uma vez por semana vem sendo cada vez mais utilizada, com toxicidade aceitável relacionada ao tratamento (GUNARATNE DA e VENESS MJ, 2018).

O tratamento radioterápico é uma opção não cirúrgica eficaz nos contextos definitivos, adjuvantes e paliativos, sendo uma modalidade de preservação de tecidos que pode oferecer um melhor resultado cosmético e funcional em comparação com a cirurgia (VENES MJ, et al., 2019). Possibilitando abordagem tanto a pequenas áreas superficiais (por exemplo, asa nasal) ou a um grande volume complexo (couro cabeludo ou base do crânio) (GARBUTCHEON-SINGH KB, 2019).

Ao decidir sobre o tratamento, devem-se considerar as comorbidades do paciente, avaliando sua expectativa de vida, capacidade cognitiva, preferências (incluindo a família) e o impacto potencial de qualquer tratamento proposto (VENES MJ, et al., 2019).

No presente estudo de caso, apresentamos o relato de uma radioterapia hipofracionada realizada em paciente com câncer de pele não melanoma em couro cabeludo, destruindo sua calota craniana e ocasionando dor intensa. O objetivo é ilustrar a abordagem frente a esses casos, que implicam em altas taxas de morbidade e declínio da qualidade de vida dos pacientes.

\section{DETALHAMENTO DO CASO}

Paciente, FTS, sexo feminino, 35 anos, lavradora na infância e hoje do lar. Veio à primeira consulta em serviço de radioterapia referindo ter percebido "feridinha" em couro cabeludo há 6 meses, que por vergonha de expor à família tratou apenas com curativos. Na ocasião queixava-se de dor intensa, parcialmente controlada com o uso de analgésico comum (paracetamol) associado a opióide fraco (codeína), em média uma vez ao dia. Referiu ainda ansiedade intensa em uso de venlafaxina com melhora parcial.

Paciente apresentou-se em bom estado geral, Escala de Performance Karnofsky (KPS): 90\%, apresentando-se com lesão úlcero-infiltrativa destrutiva localizada em região parieto-occipital direita, com extensão $>25 \mathrm{~cm}$ de diâmetro, destruindo couro cabeludo, calota craniana e infiltrando parênquima cerebral adjacente, com áreas necróticas e permeadas de pontos de sangramento, associado a odor fétido.

Trazia exame de imagem recente com espessamento heterogêneo da pele e tecido subcutâneo em região parieto-occipital direita com erosões e infiltração da calota craniana regional com extensão intracraniana extra-axial sem plano de clivagem com meninge adjacente. $\mathrm{Na}$ ocasião, o resultado anatomopatológico evidenciava apenas ceratose hiperceratótica com transformação bowenóide. Demais exames de estadiamento excluíam doença metastática. Após admissão, reencaminhada à cirurgião oncológico para nova biópsia devido alta probabilidade de doença maligna. Foi então submetida a nova biópsia e desbridamento cirúrgico de caráter higiênico. Quando nova biópsia evidenciou carcinoma espinocelular invasor grau 1 (Figura 1). 
No retorno com radioterapia, apresentava-se bem, porém com aumento da dor havendo necessidade de aumento nas doses de analgésicos. $\mathrm{Na}$ ocasião foi proposto tratamento radioterápico conformacional tridimensional com fótons na dose de 55Gy hipofracionado com caráter paliativo antiálgico e de controle local em lesão macroscópica com margens. Demonstrando bom resultado clínico (Figura 2). Paciente finalizou o tratamento de forma satisfatória e segue em seguimento clínico obtendo bom controle da doença.

Figura 1 - Lesão inicial.

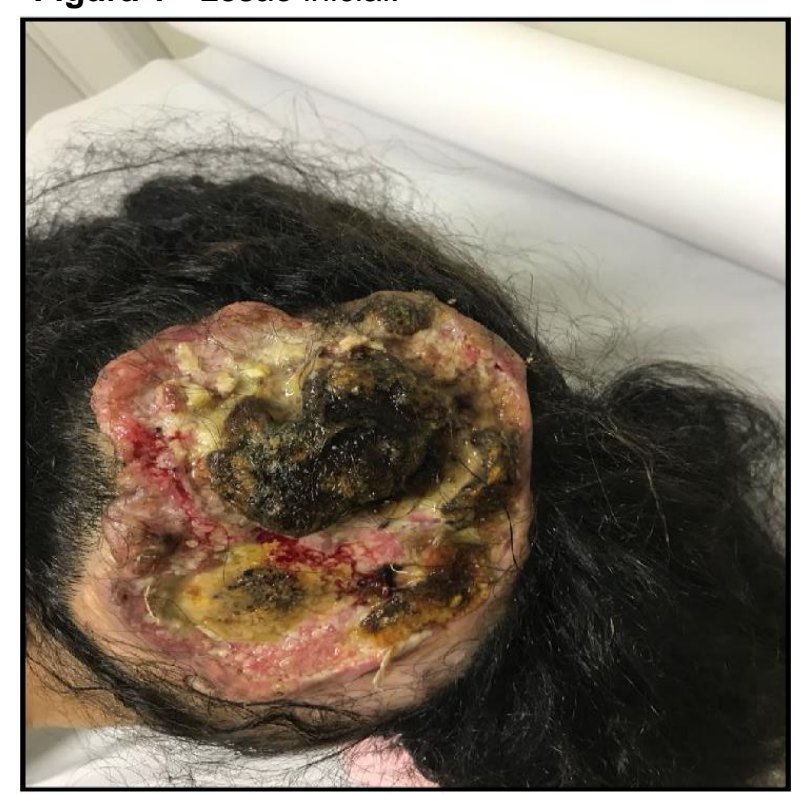

Fonte: Rodrigues VFF, et al., 2020.

Figura 2 - Lesão após desbridamento cirúrgico.

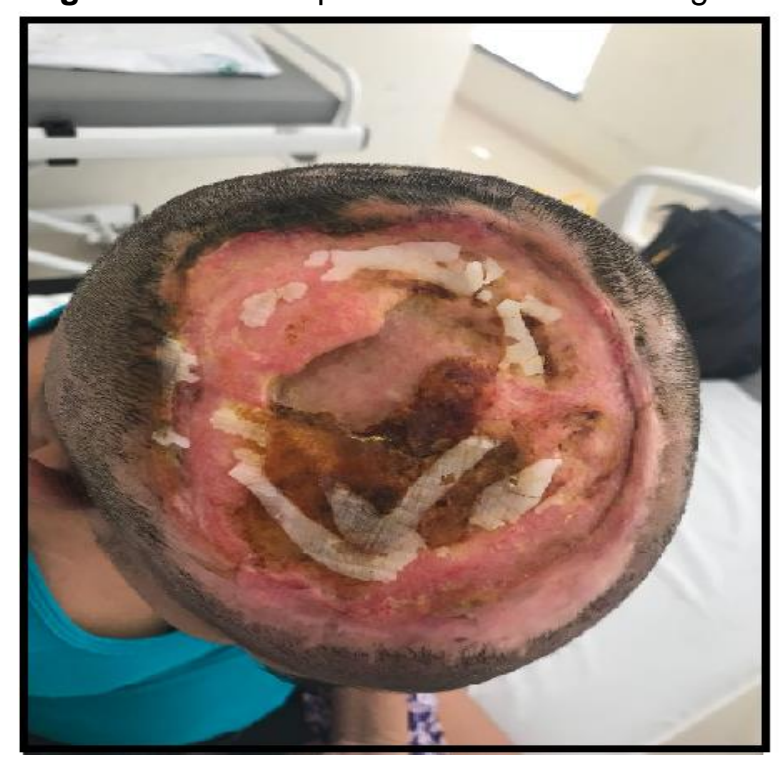

Fonte: Rodrigues VFF, et al., 2020.

A paciente possuiu um desfecho bom com um tratamento que permitiu manter o máximo de tecido do couro cabeludo, mantendo sinais vitais normais sem sintomas de infecção ou rejeição do tratamento e ainda permanece em tratamento atualmente. 


\section{DISCUSSÃO}

Dentre os casos de câncer não melanoma, o carcinoma espino celular (CEC) representa $25 \%$ da incidência. O CEC é um tumor maligno das células espinhosas da epiderme, de evolução mais rápida e com maior poder invasivo e metastático que o Carcinomas basocelulares (ENOKIHARA MY, et al., 2010).

O mais comum é que se desenvolva em áreas com maior foto-exposição (orelhas, cervical posterior e couro cabeludo) a radiação ultravioleta (UV), que é considerada o principal fator de risco para desenvolvimento da doença (SOYER HP, et al., 2015; MARGOTTO HPS, et al., 2016).

Em concordância com o estudo de caso, o paciente passou cerca de 10 anos de sua vida exercendo função laboral em lavouras sem a utilização de proteção solar em uma região de alta exposição Ultra Violetas (UV) no nordeste do Brasil (MARGOTTO HPS, et al., 2016).

No entanto, em discordância com a literatura, as lesões costumam se desenvolver em pacientes do sexo masculino em torno da quinta e sexta década de vida, e no caso apresentado a lesão surgiu por volta dos 34 anos de idade em paciente feminino. Ainda em discordância com a literatura, a paciente é classificada como fototipo Fitzpatrick 4, quando na maioria das vezes pacientes jovens acometidos pela doença possuem pele clara, com tendência a serem classificados como 1 ou 2 (CRISCIONE VD, 2009).

Cerca de 2.000 pessoas nos Estados Unidos morrem a cada ano por CPNM. Apesar disso, a morte por esses tipos de câncer é considerada incomum, porém tem suas taxas aumentadas quando localizados em topografias de couro cabeludo e pescoço, como no caso relatado (GUNARATNE DA e VENESS MJ, 2018).

Já o diagnóstico precoce desse tipo de câncer é recomendado para toda a população, necessitando que os profissionais de saúde estejam atentos às suas principais formas de apresentação: carcinoma basocelular e epidermoide (espinocelular). O primeiro apresenta-se principalmente como uma lesão (ferida ou nódulo) com bordos róseos, translúcidos ou perolados, que não cicatriza, podendo ulcerar e sangrar. Enquanto que o carcinoma epidermoide, em geral, surge como uma mancha vermelha que descama $e$ sangra formando uma ferida. Muitas vezes aparece sobre uma cicatriz, principalmente aquelas decorrentes de queimadura (COSTA GLG, 2017; BRASIL, 2016).

No caso apresentado, não foi realizado o diagnóstico precoce, visto que a paciente postergou a procura médica, cerca de 6 meses após aparecimento de lesão primária. Principalmente devido ao difícil acesso na região em que residia e, segundo a mesma, "tinha vergonha de mostrar à família". No entanto, após a procura, foi solicitada biópsia, mandatória para firmar-se o diagnóstico (COSTA GLG, 2017; BRASIL, 2016).

Existem várias classificações para o CEC, como: a da American Joint Comitee on Cancer (AJCC), a de Clark e a de Broder. Assim, a classificação de Broder categoriza o tipo histológico por graus de I a IV, onde os tumores com mais de $75 \%$ das células diferenciadas são classificados em grau I e aqueles com menos de $25 \%$ das células diferenciadas possuem classificação grau IV (VIEIRA VM e JOUBERT U, 2019; RIBERO S, et al., 2016).

Concomitantemente, segundo resultado da biópsia. Houve a presença de CEC invasivo com grau histológico tipo I. Isso significa que houve invasão tecidual restrita à epiderme, segundo o nível (classificação) de Clark que quantifica o grau de penetração da neoplasia referida em graus de I a V. Assim, lesões de nível II são aquelas que apresentam invasão até a derme papilar; de nível III aquelas que invadem toda a derme papilar sem chegar a derme reticular; de nível IV quando atingem a derme reticular; e de nível V aquela que se estende até a hipoderme (VIEIRA VM e JOUBERT U, 2019; RIBERO S, et al., 2016).

Segundo a literatura, características do CEC primário podem servir como preditores de neoplasia de pior prognóstico. O AJCC estabeleceu critérios para estadiamento de tumores primários de alto risco e considera: o diâmetro (> $2 \mathrm{~cm}$ ), a espessura ( $>2 \mathrm{~mm}$ ou nível de Clark $>\mathrm{IV}$ ), a invasão perineural, a localização (orelha e lábio), e a diferenciação (pouco diferenciado ou indiferenciado) (NUÑO-GONZÁLEZ A, et al., 2012; CH'NG S, et al., 2013). Além disso, a presença de lesão recorrente. A escolha terapêutica deve levar em conta os fatores prognósticos. De acordo com tais critérios, a paciente descrita apresentou CEC de 
alto risco, levando-se em conta a extensão da lesão, com diâmetro maior que $25 \mathrm{~cm}$ (TEIXEIRA LR, et al., 2015).

A maioria das lesões de CEC são de baixo risco, com significativa diferenciação celular, originárias de ceratoses actínicas, consideradas como possíveis lesões precursoras. No entanto, como no caso apresentado, somado ao diagnóstico tardio, há as formas de alto risco com indiferenciação celular, que geralmente surgem a partir da Doença de Bowen (DB) e tornam-se invasivas, podendo causar metástase. A DB corresponde a um carcinoma espinocelular in situ, ou seja, de localização intra-epidérmica e crescimento lento (ENOKIHARA MY, et al., 2010).

Após diagnóstico definitivo do CEC, confirmado através da biópsia, o tratamento deve ser realizado na dependência de cada tipo específico. A da abordagem terapêutica depende de alguns fatores, como o tamanho, o tipo histológico e localização. As opções terapêuticas podem ser a exérese cirúrgica com margem de segurança, cirurgia micrográfica de Mohs, criocirurgia, terapia fotodinâmica, imunomoduladores tópicos, interferons, quimioterapia sistêmica e radioterapia. Quando detectado precocemente, o CEC apresenta alto índice de cura, no entanto tem potencial de recorrer no local e provocar metástase. Sobretudo, quando o tempo entre manifestação da doença e diagnóstico é prolongado, resultando em um diagnóstico de doença localmente avançada. Evidenciando-se a importância dos cuidados paliativos para o gerenciamento adequado do tratamento. No caso em questão a paciente foi submetida a radioterapia paliativa devido impossibilidade de abordagem cirúrgica curativa e pela necessidade de conter 0 crescimento destrutivo da lesão (LAVAUD J, et al., 2019).

No que se refere ao manejo das feridas, o objetivo é a cicatrização, contudo, como a doença foi diagnosticada como localmente avançada, uma abordagem com cuidados paliativos foi necessária, de forma que possibilitasse proporcionar o controle dos sintomas da lesão e o conforto do paciente em relação à ferida. Neste sentido, os cuidados paliativos planejados foram capazes de fornecer o alívio das dores e a cicatrização da área, respeitando o princípio norteador da paliação (CHUA B, et al., 2019).

Portanto, como observado na literatura, a paliação por meio da radioterapia hipofracianada foi uma abordagem terapêutica bem tolerada pela paciente. Resultando em melhora de sua qualidade de vida, uma vez que proporcionou controle álgico, interrupção do crescimento da lesão e elevação da autoestima (CHUA B, et al., 2019).

O relato apresentado destaca a relevância do diagnóstico precoce do CEC através de seu rastreamento e detecção. Visto que, por ser uma área de intensa exposição solar, o diagnóstico é feito ainda quando a lesão se apresenta pequena. $O$ que remete à falta de informação da paciente por não ter noção da gravidade do caso e ter procurado auxílio médico quando a doença já estava estágio avançado por não ter encontrado fácil acesso ao serviço de saúde, uma vez que ao diagnóstico a lesão se apresentava com grande extensão e já se infiltrando calota craniana, o que não é comum. Enfatiza-se a necessidade de sua prevenção com ações de educação em saúde direcionadas à população, com estímulo a proteção individual e atuação sobre elementos modificadores da doença.

\section{REFERÊNCIAS}

1. BRASIL. Instituto Nacional de Câncer José Alencar Gomes da Silva. Estimativa 2016: Incidência de Câncer no Brasil. Rio de Janeiro: INCA, 2016.

2. BRAY F, et al. Global cancer statistics 2018: GLOBOCAN estimates of incidence and mortality worldwide for 36 cancers in 185 countries. CA Cancer J Clin. 2018;68(6):394-424.

3. CRISCIONE VD, et al. Actinic keratoses: natural history and risk of malignant transformation in the Veterans Affairs Topical Tretinoin Chemoprevention Trial. Cancer. 2009; 1;115(11):2523-30.

4. COSTA GLG. Estudo restrospectivo dos casos de câncer de pele diagnosticados no Hospital de Câncer de Mato Grosso. Dissertação (Mestrado). São Paulo, 2017. 37p.

5. CH'NG S, et al. Relevance of the primary lesion in the prognosis of metastatic cutaneous squamous cell carcinoma. Head Neck. 2013;35(2):190-4.

6. CHUA B, et al. Radiotherapy for early non-melanoma skin cancer. Oral Oncology, 98, 96-101.

REAC/EJSC | Vol. 12 | e4101 | DOI: https://doi.org/10.25248/reac.e4101.2020

Página 6 de 7 
7. ENOKIHARA MY, et al. Carcionoma basocelular e Carcionoma espinocelular. Rotinas de diagnóstico e tratamento da Sociedade Brasileira de Dermatologia. São Paulo: Ac Farmacêutica; 2010: 29-35

8. GARBUTCHEON-SINGH KB, VENES MJ. The role of radiotherapy in the management of non-melanoma skin cancer. Australasian Journal of Dermatology. 2019. 60(4):265-272

9. GUNARATNE DA, VENESS MJ. Efficacy of hypofractionated radiotherapy in patients with non-melanoma skin cancer: Results of a systematic review. Journal of Medical Imaging and Radiation Oncology, 2018. 62(3), $401-411$.

10. LONG DL, et al. Medicina Interna de Harrison. 18 ed. Porto Alegre, RS: AMGH Ed., 2013. 2v.

11. LAVAUD J, et al. Pembrolizumab and concurrent hypo-fractionated radiotherapy for advanced non-resectable cutaneous squamous cell carcinoma. European Journal of Dermatology, 29(6), 636-640.

12. MARGOTTO HPS, et al. Fotoexposição e fatores de risco para câncer de pele: avaliação de hábitos e conhecimentos da população participante da campanha de prevenção ao câncer de pele em Morro Redondo/RS. Rev AMRIGS. 2016;60(1):32-7.

13. RIBERO S, et al. Squamocellular Carcinoma of the Skin: Clinicopathological Features Predicting the Involvement of the Surgical Margins and Review of the Literature. Dermatology. 2016; 232(3): 279-284.

14. SOYER HP, et al. Queratose actínica, Carcinoma basocelular e carcinoma espinocelular. In: Bolognia JL, Jorizzo JL, Schaffer JV. Dermatologia. 3a ed. Rio de Janeiro: Elsevier; 2015. p.5156-215.

15. TEIXEIRA LR, et al. Abordagem do carcinoma espinocelular de alto risco no couro cabeludo: série de casos. Surg Cosmet Dermatol 2015;7(2):166-70.

16. VENES MJ, et al. Current Role of Radiotherapy in Non-melanoma Skin Cancer. Clinical Oncology. 2019, 31(11): 749-758.

17. VIEIRA VM, JOUBERT U. Carcinoma Espinocelular em couro cabeludo: relato de caso. Temas em Saúde 2019, 19(4): 65-76.

18. NUÑO-GONZÁLEZ A, et al. High-Risk Cutaneous Squamous Cell Carcinoma. Actas Dermosifiliogr. 2012;103(7):567-78. 